\title{
Redimensionamento da Computação em Processo de Ensino na Educação Básica: O pensamento Computacional, o Universo e a Cultura Digital.
}

\author{
Melquisedec Sampaio Leite ${ }^{1}$, Sônia Regina Fortes da Silva ${ }^{1}$ \\ ${ }^{1}$ Universidade de Pernambuco, Campus Garanhuns (UPE) \\ CEP 55.294-902 - Garanhuns - PE - Brasil \\ melquisedec.leitedupe.br, fortes.sonialgmail.com
}

\begin{abstract}
This article aimed to investigate how computing is being resized in education in the world and in Brazil, by analyzing the axes of Computer Teaching for a proposal of educational activities that develop certain skills and competences, strengthening computational thinking, the universe and digital culture of children and young people in basic education. For this, data were collected in the literature on political issues in Brazil, computational thinking and the universe of digital culture, relating these data to the skills and competences proposed in SAEB and in the Curriculum Guidelines of Computer Teaching, SBC for basic education.

Resumo. Este artigo teve como objetivo investigar como a Computação está sendo redimensionada em educação no mundo e no Brasil, através de análise dos eixos do Ensino de Computação para uma fundamentação de proposta de atividades educativas, que desenvolvam determinadas habilidades e competências, fortalecendo o pensamento computacional, o universo e a cultura digital de crianças e jovens na educação básica. Para isso, foram levantados dados na literatura sobre as questões políticas no Brasil, o pensamento computacional e o universo de cultura digital, relacionando estes dados às habilidades e competências propostas no SAEB e nas Diretrizes Curriculares do Ensino de Computação, da SBC para a educação básica.
\end{abstract}

\section{Introdução}

Nos últimos anos, vêm ocorrendo grandes transformações nos campos da ciência e da tecnologia. Essas mudanças têm forte impacto na educação escolar e alertam para a necessidade de se adotar novas formas de ensino, fazendo uso de novas ferramentas tecnológicas que estão cada vez mais presentes no dia a dia das pessoas. [Kenski 2013] destaca que tecnologia é poder, assim como a educação. Ambas podem tornar o ser humano capaz de exercer função ativa na sociedade.

Acrescenta ainda [Moran 2007], que a educação não é um processo apenas da escola, mas de toda a sociedade e que afeta todas as pessoas, seja através da transmissão de ideias, valores, informações dentre outros. Todos são educadores e aprendizes, pois transmitem e recebem conhecimento. A escola é o espaço institucional onde ocorre a chamada educação formal. Políticas são definidas pelo governo e pelos órgãos de educação para nortear os caminhos a serem seguidos pela educação na escola.

A popularização da internet vem caracterizando o século XXI, como a sociedade da informação, com avanços técnicos e científicos que provocam mudanças rápidas no modo de vida das pessoas. A internet hoje é indispensável às tarefas cotidianas e na escola. Nesse sentido, [Moran 2007, p.9] coloca a seguinte ideia: 
VI Congresso Brasileiro de Informática na Educação (CBIE 2017)

Anais dos Workshops do VI Congresso Brasileiro de Informática na Educação (WCBIE 2017)

Escolas não conectadas são escolas incompletas (mesmo quando
didaticamente avançadas). Alunos sem acesso contínuo às redes digitais
estão excluídos de uma parte importante da aprendizagem atual: do
acesso a informação variada e disponível on-line, da pesquisa rápida em
bases de dados, bibliotecas digitais, portais educacionais; da participação
em comunidades de interesse, nos debates e publicações on-line, enfim,
da variada oferta de serviços digitais.

Desta forma, a escola sofre influência do processo de informatização e novas habilidades são exigidas dos educandos. Sendo estas: a capacidade de trabalhar em grupo, a capacidade de resolver um problema a partir de um conceito já construído, capacidade de resolver cálculos mentalmente, de associar os assuntos estudados nas disciplinas escolares com o contexto do mundo real.

Nesse contexto evolutivo e transitório da educação, das tecnologias e da sociedade, este artigo pretende investigar como o pensamento computacional está sendo redimensionado em educação, através de uma busca na literatura, tanto no mundo, como no Brasil e em Pernambuco.

Para abordar esta questão busca-se nesta pesquisa investigar como a computação está sendo redimensionada em educação, no mundo e no Brasil, através de análise dos eixos do Ensino de Computação para uma fundamentação de proposta de atividades educativas, que desenvolvam determinadas habilidades e competências, fortalecendo o pensamento computacional, o universo e a cultura digital de crianças e jovens na educação básica. Para isto, uma análise dos eixos do Ensino de Computação para uma fundamentação de proposta de atividades educativas será necessária, fortalecendo os eixos do ensino-aprendizagem de crianças e jovens na educação básica.

\section{Computação Educacional}

\subsection{Formação Docente para a Computação Educacional no Contexto Político}

O Curso de Licenciatura em Computação, atualmente, é a etapa da educação superior que habilita estudantes para a docência em Computação e Informática na Educação Básica. É um Curso relativamente novo no Brasil, sendo expandido após a promulgação da Lei No 9.394, do CNE, em 1996, em decorrência da introdução de Informática e Computação, nos debates nacionais para a formação de competências e habilidades para um mercado em expansão, na década de 80 . Inicia sua abrangência na educação em graduação, nos Cursos de Ciências Biológicas, Física e Matemática, bem como na educação básica, em sua última etapa, no ensino médio, no final da década de 90 e início deste século.

Como se pode ver, no Brasil, o mercado está se abrindo para esta área, com novos Cursos de Informática / Computação, tanto na educação básica como superior. Algumas Escolas de Aplicação de Universidades que têm a Licenciatura em Computação, já incluíram o Ensino de Computação em sua malha curricular, sendo esta uma conquista. Algumas escolas de referência estaduais e escolas privadas no Brasil já possuem em sua proposta curricular ensino de Robótica e Computação.

Após a promulgação da LDBEN/96, o Estado ofereceu a disciplina de Informática, em escolas públicas do ensino médio e na rede particular, no ensino fundamental e médio, ofertando cursos de pequena duração aos professores interessados em ministrar estas aulas, devido à existência de somente um curso de Licenciatura em Computação, na região de Recife, na UFRPE. No início deste século, suspende-se a oferta desta disciplina, devido à questões políticas, para abertura de concurso público 
para professores e a disponibilidade de aumentar a carga horária para acréscimos à matriz curricular de referência, sendo utilizada como abordagem até então, que seu potencial é mais técnico e não pedagógico. Recentemente, retorna este debate com força, a partir do Plano Nacional de Educação [Brasil 2015], que orienta o uso de tecnologias em sua Meta 07, quando se observou a disseminação desta área de conhecimento através da Robótica e de trabalhos sobre o ensino de Computação em Congressos de Tecnologias em Educação, tanto de redes privadas, quanto de redes públicas, no nordeste, sul e sudeste do Brasil.

No nordeste, em Pernambuco e na Paraíba, observaram-se ações educativas públicas de Robótica e Programação, nas Secretarias de Educação, na Prefeitura de Recife, Caetés e de João Pessoa. Neste sentido, torna-se importante discutir a formação desses profissionais que atuam na educação básica com as tecnologias da Informática e de Computação.

No mundo, o ensino de Computação se expandiu nos Estados Unidos, na Europa (Alemanha, França, dentre outros) e outros países do hemisfério norte, como o Japão, a Coréia. No Brasil, o debate está entre a SBC e os representantes da BNCC, existindo uma proposta para o ensino de Computação.

Todos estes países têm sua proposta curricular, sendo estas discutidas com os estudantes das Licenciaturas e pela SBC. Portanto, não se pode afirmar que não existe uma proposta curricular, mas sim, que necessita de vontade política dos Estados e Municípios para esta implementação, como vem fazendo a Secretaria de Educação de Recife que já discute sua proposta curricular de ensino de Computação, após sua experiência com Robótica na educação básica.

Neste movimento político educacional, é que a SBC está sendo chamada para apresentar uma proposta de diretrizes curriculares para o ensino de Computação na educação básica e está negociando esta Diretriz Curricular de Ensino de Computação DCEC com os representantes da Base Nacional Comum Curricular - BNCC no Ministério de Educação e Cultura - MEC. Para apresentação dessa proposta, foi criada uma Comissão de Educação específica, formada por diversas Universidades do Sul e Sudeste e, no Nordeste, a Universidade de Pernambuco.

As orientações da BNCC [Brasil 2017], em sua terceira versão, foi divulgada até este momento até o ensino fundamental, restando apresentar a proposta para o ensino médio. A proposta de ensino de Computação contida na BNCC, apresenta-se focando o pensamento computacional de forma estrita, pois está integrado à Matemática e, não como área, como orienta a Sociedade Brasileira de Computação - SBC. Entretanto, compreendendo a luta por diretrizes curriculares como fator histórico, considerando-se a trajetória em sua forma gradativa, em um processo de conquistas de campo de ação curricular nas escolas. Como exemplo, a área de Matemática, secular, levou 21 anos de luta dos Matemáticos para ter o reconhecimento de um espaço como área na BNCC. Neste sentido, espera-se que a trajetória exitosa da Computação Educacional seja mais rápida, embora aguarda-se que esta estará presente no Ensino Médio, enquanto como área perpassa por toda a educação básica. Nesta proposta atual da BNCC aborda-se o pensamento computacional de forma estrita, tendo sido emitido um Parecer da SBC sobre este ranço, apresentando as competências e habilidades do Ensino de Computação para todas as etapas da educação Básica, estudo desenvolvido pela sua Comissão de Educação, específica para esta proposição. 
Nesse contexto, é indispensável ressaltar a existência de algumas competências gerais para o ensino de Computação, contidas no Sistema de Avaliação da Educação Básica - SAEB (2011), como: a) Domínio do conhecimento da área e das ferramentas computacionais; b) Capacidade de realizar trabalhos vinculados com o projeto pedagógico da escola utilizando os conceitos da Ciência da Computação; c) Mostrar aos alunos como abstrair as informações mais importantes num determinado problema, de forma que essas informações sejam significativas para os alunos, permitindo que eles a compreendam e elaborem suas próprias soluções; d) Capacidade de coordenar atividades em que se organize a turma em grupos, desenvolvendo nos alunos a capacidade de trabalhar em cooperação uns com os outros, a capacidade de liderança, expressão, interação e troca de informações. Entretanto, para se efetivar esta proposta necessita-se de orientações políticas de âmbito nacional como efeito cascata nos sistemas de ensino, colocando o Brasil dentre os demais que reconheceram a importância do desenvolvimento do pensamento computacional em seu universo e cultura digital na sociedade contemporânea.

\subsection{Pensamento Computacional no Mundo e no Brasil}

[Blikstein 2008] define que o pensamento computacional, como a capacidade de saber usar o computador como um instrumento de aumento do poder cognitivo e operacional humano, dessa forma, contribuindo com o aumento da produtividade, inventividade, e criatividade. Ainda afirma que a primeira etapa para se "pensar computacionalmente" é identificar as atividades cognitivas que podem ser feitas de forma mais rápida e eficiente por um computador. A segunda etapa seria transferir o que não é essencialmente humano para o computador, para que este realize as tarefas.

O raciocínio computacional vai muito além do simples uso do computador, ele expande a capacidade do pensamento humano para resolver problemas, mesmo sem a presença da máquina. Já existem trabalhos nesse sentido como, por exemplo, o projeto da Computação Desplugada de Bell e Witten, (1995). Este projeto apresenta alternativas de ensino da Computação por meio de atividades lúdicas e analogias do cotidiano, não utilizando recursos de hardware e/ou software. Este método de trabalho tem despertado interesse de pesquisadores e professores em diversos países. O ensino de Computação sem a necessidade de hardware e/ou software especializados possibilita a realização das práticas pedagógicas em diferentes estruturas escolares.

Segundo [Yadav et. all. 2017], em vários países como a Austrália, EUA e Reino Unido, cresceu o entusiasmo nos últimos anos para o ensino de Computação. Em 2012, a Royal Society no Reino Unido colocou o seguinte: Toda criança deve ter a oportunidade de aprender conceitos e princípios da computação, incluindo a ciência da computação e as tecnologias da informação, desde o início do ensino primário em diante, e aos 14 anos podem escolher estudar para obter uma qualificação reconhecida nessas áreas. Em 2016, o College Board nos EUA lançou um novo currículo de Ciência da Computação para escolas secundárias, chamado "Princípios da Ciência da Computação", enfocando a exposição dos alunos ao pensamento computacional e práticas para ajudá-los a entender como a computação influencia o mundo.

Em países como Estados Unidos e Canadá, o modelo Model Curriculum for K12 Computer Science (CSTA K-12) é adotado para o ensino de computação. Segundo as diretrizes do k-12, o aluno deve desenvolver, através do Pensamento Computacional, habilidades para resolver problemas numa forma que pode ser implementada em um computador, envolvendo um conjunto de conceitos, como abstração, recursão, iteração, 
VI Congresso Brasileiro de Informática na Educação (CBIE 2017)

Anais dos Workshops do VI Congresso Brasileiro de Informática na Educação (WCBIE 2017)

dentre outras. As diretrizes CSTA para o ensino de computação da educação infantil ao ensino médio são baseadas em um modelo em três níveis (Figura 1). O nível 1 fornece os padrões de aprendizagem para os estudantes do infantil até ao sexto ano, o nível 2 fornece os padrões de aprendizagem para estudantes entre o sexto e o nono ano, e o nível 3 fornece os padrões de aprendizagem para os alunos do ensino médio [Wangenheim, Et. All.. 2014]. Esses limites especificados para cada nível podem variar de escola para escola.

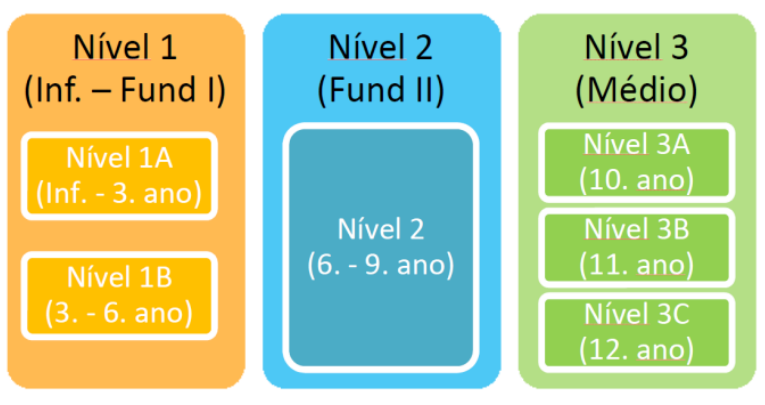

Figura 1. Níveis de Ensino de Computação

No Nível 1, são apresentados os conceitos fundamentais de Ciência da Computação a alunos do ensino fundamental. São incorporadas competências, como: criatividade e exploração, aplicadas a outras áreas curriculares, tais como: ciências sociais, língua, matemática e ciência. No Nível 2, o Pensamento Computacional começa a ser utilizado para resolução de problemas. No Nível 3, os alunos aprendem a dominar conceitos mais avançados de ciência da computação e aplicar esses conceitos para desenvolver artefatos virtuais e reais [Wangenheim, Et. All.. 2014].

Além da iniciativa de informatizar as escolas, pode-se dizer que no Brasil os esforços para iniciar as discussões acerca do Pensamento Computacional na Educação Básica começaram com a oferta dos cursos de Licenciatura em Computação - LC. O licenciado em Computação é um professor da educação básica que tem como missão pensar o uso efetivo das tecnologias na escola, utilizando-se de ferramentas como as redes de informação, as tecnologias sociais e o conteúdo digital [Cambraia e Scaico 2013].

\section{Estratégia de Ação}

A estratégia foi a aplicação de um exercício sobre os eixos da Proposta da SBC a uma turma do V período do curso de Licenciatura em Computação - LC da Universidade de Pernambuco - Campus Garanhuns/PE, buscando saber a compreensão dos estudantes, futuros professores de Computação sobre as competências e habilidades que poderiam ser ensinadas na educação básica. Estiveram presentes 20 graduandos, que para esse estudo, foram divididos em 7 grupos, sendo 6 constituídos por 3 membros e um grupo com dois. Esses eixos foram colocados aos graduandos de acordo com o quadro a seguir.

Quadro 1. Propositivo ao Estudo - Eixos do Ensino de Computação da SBC

\begin{tabular}{|l|l|l|}
\hline \multicolumn{1}{|c|}{ Pensamento Computacional } & \multicolumn{1}{|c|}{ Ecossistema Digital } & \multicolumn{1}{c|}{ Cultura Digital } \\
\hline $\begin{array}{l}\text { Abstração: selecionar e utilizar } \\
\text { modelos e representações adequadas } \\
\text { para descrever informações e e } \\
\text { processos, e técnicas para construir } \\
\text { soluções algorítmicas; }\end{array}$ & $\begin{array}{l}\text { Codificação: entender como } \\
\text { informações podem ser descritas e } \\
\text { armazenadas; }\end{array}$ & $\begin{array}{l}\text { Computação e Sociedade: } \\
\text { compreender o impacto e } \\
\text { decorrências da revolução digital e } \\
\text { dos avanços do ecossistema digital } \\
\text { na humanidade; }\end{array}$ \\
\hline
\end{tabular}


VI Congresso Brasileiro de Informática na Educação (CBIE 2017)

Anais dos Workshops do VI Congresso Brasileiro de Informática na Educação (WCBIE 2017)

Automação: descrever as soluções de forma que máquinas possam executar partes ou todo o algoritmo proposto, construir modelos computacionais de sistemas complexos;

Análise: analisar criticamente os problemas e soluções para identificar não somente se existem que podem ser automatizadas, mas também avaliar a eficiência e a correção destas soluções. computadores e os diferentes níveis de relação entre hardware e software;

Distribuição: entender como se dá a comunicação entre diferentes dispositivos digitais, como os dados são transmitidos, como é garantida a integridade e segurança no mundo digital, entender a estrutura da internet.
Fluência tecnológica: utilizar de forma eficiente e crítica ferramentas que auxiliem a obter, analisar, sintetizar e comunicar informações de formatos e com fins diversos;

Ética Digital: analisar de forma crítica, questões éticas e marais que surgiram com o ecossistema digital.

De posse dessa informação, os graduandos em LC elaboraram propostas e atividades para o ensino de Computação nas etapas da Educação Básica. Em seguida, foi feita a análise das respostas dadas pelos participantes, confrontadas com a proposta da SBC, destacando as aproximações e os afastamentos observados na compreensão dos estudantes.

\section{Resultados e Análise}

\subsection{Habilidades e Competências Conforme os Eixos da Proposta da SBC}

Durante a realização do exercício, a discussão pôde ser aberta ou fechada, tendo alguns grupos interagidos, apresentando seus pensamentos. A interação foi como uma reunião de professores, sugerindo e discutindo as possibilidades e limites das atividades propostas.

Os participantes contribuíram para este estudo, num primeiro momento, com propostas de competências e habilidades para o Ensino de Computação, conforme os eixos das propostas da SBC:

Quadro 2. Propostas de Competências e Habilidades

\begin{tabular}{|c|c|c|c|}
\hline Educação Básica & $\begin{array}{c}\text { Pensamento } \\
\text { Computacional }\end{array}$ & Ecossistema Digital & Cultura Digital \\
\hline Educação Infantil & $\begin{array}{l}\text { A possibilidade de } \\
\text { trabalhar com a abstração } \\
\text { no processo de construção } \\
\text { do conhecimento, pois } \\
\text { entende-se que os alunos } \\
\text { já são capazes de entender } \\
\text { um processo, sem se } \\
\text { aprofundar em como } \\
\text { funciona; } \\
\text { Aprendizagem através da } \\
\text { análise e compreensão de } \\
\text { problemas e criação de } \\
\text { possíveis soluções } \\
\text { (algoritmos simples). }\end{array}$ & $\begin{array}{l}\text { Entender e vivenciar a } \\
\text { Comunicação Digital; } \\
\text { Entender e diferenciar } \\
\text { hardware e software; } \\
\text { Compreender como as } \\
\text { informações são escritas } \\
\text { e armazenadas; } \\
\text { Interagir com } \\
\text { dispositivos móveis e } \\
\text { executar funções } \\
\text { simples (jogar, digitar, } \\
\text { etc.). }\end{array}$ & $\begin{array}{l}\text { Entender a relação entre } \\
\text { Computação e } \\
\text { Sociedade através da } \\
\text { comparação entre } \\
\text { passado e presente por } \\
\text { meio de imagens; } \\
\text { Identificar os recursos } \\
\text { digitais, suas finalidades } \\
\text { e importância; } \\
\text { Explorar o contexto } \\
\text { histórico da evolução } \\
\text { dos computadores. }\end{array}$ \\
\hline Ensino Fundamental I & $\begin{array}{l}\text { Elaborar, entender e } \\
\text { resolver problemas } \\
\text { através de ferramentas } \\
\text { computacionais; } \\
\text { Desenvolver a lógica; }\end{array}$ & 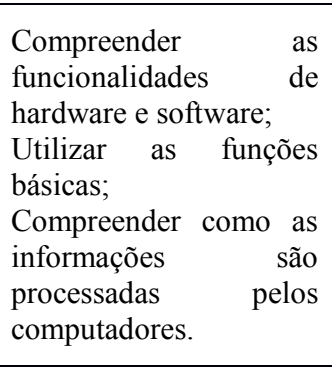 & $\begin{array}{l}\text { Compreender os } \\
\text { impactos atuais e futuros } \\
\text { dos avanços } \\
\text { tecnológicos; } \\
\text { Debater de forma crítica } \\
\text { as questões éticas que } \\
\text { envolvem os avanços } \\
\text { tecnológicos; } \\
\text { Explorar o uso eficiente } \\
\text { de ferramentas digitais. }\end{array}$ \\
\hline
\end{tabular}


VI Congresso Brasileiro de Informática na Educação (CBIE 2017)

Anais dos Workshops do VI Congresso Brasileiro de Informática na Educação (WCBIE 2017)

\begin{tabular}{|c|c|c|c|}
\hline Ensino Fundamental II & $\begin{array}{l}\text { Trabalhar com abstração, } \\
\text { automação, codificação e } \\
\text { processamento; } \\
\text { Analisar padrões e } \\
\text { entender o processo de } \\
\text { reconhecimento. }\end{array}$ & $\begin{array}{l}\text { Compreender como as } \\
\text { informações são } \\
\text { processadas } \\
\text { diferentes níveis; } \\
\text { Representar } \\
\text { atividades que hardware } \\
\text { e software } \\
\text { desempenham; } \\
\begin{array}{l}\text { Explorar a linguagem } \\
\text { de máquina através do } \\
\text { código binário. }\end{array}\end{array}$ & $\begin{array}{l}\text { Argumentar sobre } \\
\text { questões éticas e morais } \\
\text { através de exemplos de } \\
\text { casos reais ocorridos na } \\
\text { sociedade; }\end{array}$ \\
\hline $\begin{array}{c}\text { Ensino Médio Regular e } \\
\text { Técnico }\end{array}$ & $\begin{array}{l}\text { Realizar e estabelecer } \\
\text { modelos e representações } \\
\text { adequadas para descrever } \\
\text { e construir algoritmos e } \\
\text { suas soluções. No caso do } \\
\text { EMT, adiciona-se a } \\
\text { construção de software, } \\
\text { aplicativos ou páginas } \\
\text { web para representar estas } \\
\text { soluções; o Pensamento } \\
\text { Associar o com } \\
\text { Computacional como } \\
\text { outras ciências, como } \\
\text { matemática, física, } \\
\text { biologia, dentre outras; } \\
\text { Utilizar o PC para } \\
\text { resolver problemas reais } \\
\text { de diversas áreas do } \\
\text { conhecimento. }\end{array}$ & $\begin{array}{l}\text { Compreender como } \\
\text { funciona a comunicação } \\
\text { entre dispositivos } \\
\text { digitais, de forma a } \\
\text { reconhecer que } \\
\text { dispositivo utilizar para } \\
\text { cada situação; } \\
\text { Trabalhar com robótica, } \\
\text { principalmente no } \\
\text { EMT; } \\
\text { Desenvolver softwares } \\
\text { simples, com } \\
\text { ferramentas lúdicas, a } \\
\text { exemplo do Scratch, no } \\
\text { caso do EMR e com } \\
\text { ferramentas mas } \\
\text { complexas e linguagens } \\
\text { como Java, Prolog e } \\
\text { outras no caso do EMT; } \\
\text { Entender e realizar } \\
\text { atividades sobre redes } \\
\text { de computadores e } \\
\text { segurança de sistemas } \\
\text { de forma básica no } \\
\text { EMR e aprofundada no } \\
\text { EMT. }\end{array}$ & 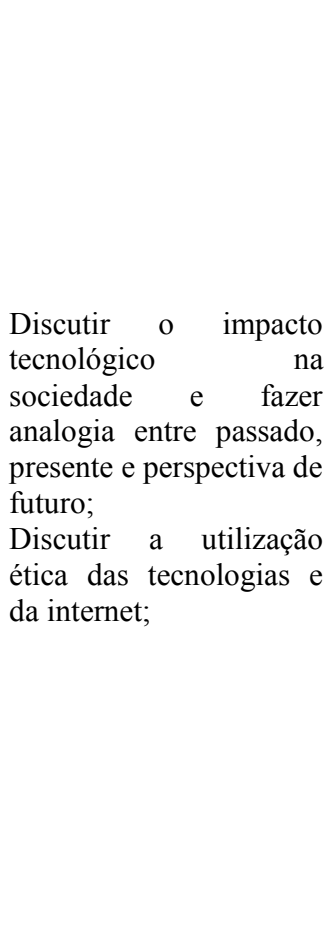 \\
\hline
\end{tabular}

Considerou-se que os participantes apresentaram uma perspectiva relacional com o que se espera do ensino de computação, neste momento em que se discute a sua inserção não só no Curso Técnico, mas também nas demais etapas da educação básica.

As Redes Estaduais de Ensino Técnico orientam Cursos de Informática, de Redes de computadores, de Manutenção e Suporte de Informática, Hospedagem em redes de Computadores, Logística e Redes de Computadores, Informática para Internet, Programação de Jogos digitais e Multimídias, nas regiões do estado de Pernambuco. Nas Escolas Técnicas Federais, encontram-se o Curso de Informática e de manutenção e Suporte de Informática, Operador de computador, Computação Gráfica, Hospedagem, Informática para Internet, Manutenção e suporte em Informática, Redes de Computadores, com a malha curricular predominantemente de Computação e, em todos os Cursos a disciplina de Informática Básica.

Nos Estágios Obrigatórios constatou-se que os estudantes, ao escolherem qualquer curso técnico, demonstra alta dificuldade em Informática Básica, necessitando de reforço ou nivelamento nesta área, a fim de que tenham êxito nos cursos. Isto fundamenta a necessidade deste conhecimento nas etapas da educação básica, anteriores ao ensino médio, e sua importância em todas as escolas públicas e privadas. 
VI Congresso Brasileiro de Informática na Educação (CBIE 2017)

Anais dos Workshops do VI Congresso Brasileiro de Informática na Educação (WCBIE 2017)

\subsection{Atividades Relacionadas aos Eixos das Propostas da SBC}

A segunda parte do estudo consistiu nas propostas de atividades, pelos mesmos graduandos de LC que sugeriram as competências. Essas atividades serão aqui enumeradas, de acordo com seu respectivo Eixo:

Quadro 2. Propostas de Atividades

\begin{tabular}{|c|c|}
\hline Eixos & Atividades \\
\hline $\begin{array}{l}\text { Pensamento } \\
\text { Computacional }\end{array}$ & $\begin{array}{l}\text { Computação desplugada, respeitando as competências para cada nível da Educação Básica; } \\
\text { Expor problemas do mundo real, abordando inclusive outras ciências, solicitando que os } \\
\text { educandos abstraiam e apresentem soluções diversas; } \\
\text { Apresentar problemas de acordo com os critérios do tópico anterior para serem resolvidos } \\
\text { através de algoritmos; } \\
\text { Por meio de Gamificação e PBL, elaborar problemas para serem resolvidos em equipes, de } \\
\text { forma computacional e não computacional, gerando discussões e fortalecendo o trabalho em } \\
\text { equipe, além de desenvolver o conceito de liderança; } \\
\text { Realizar atividades lúdicas, como teatro por exemplo, representando processos de um } \\
\text { programa, sistema operacional, protocolos de internet, dentre outros; } \\
\text { Problemas matemáticos envolvendo lógica; }\end{array}$ \\
\hline $\begin{array}{l}\text { Ecossistema } \\
\text { Digital }\end{array}$ & $\begin{array}{l}\text { Atividade de debate e pesquisa sobre os meios de comunicação e transmissão existentes e a } \\
\text { evolução dos mesmos; } \\
\text { Atividade comparativa para fomentar o entendimento e exposição comparando hardware e } \\
\text { software de maneira lúdica, inclusive levando para a sala de aula, componentes de hardware, } \\
\text { como monitores, placas, memórias e outros artefatos, além de programas e aplicativos para } \\
\text { representar os softwares; } \\
\text { Caracterizar como funciona o sistema de redes de computadores, especificando a sua } \\
\text { evolução; } \\
\text { Simulação, através de software específico, para conexão de redes de computadores; } \\
\text { Estudo prático utilizando estrutura de dados, onde o aluno terá de criar um relatório com os } \\
\text { códigos e com suas palavras definir para que o código serve e comentar o mesmo; } \\
\text { Em grupos, os alunos deverão criar textos, convertê-los para binários, trocar com outros } \\
\text { grupos e realizar o processo inverso; }\end{array}$ \\
\hline Cultura Digital & $\begin{array}{l}\text { Fazer uma linha do tempo a partir da definição de ética digital mostrando a evolução digital; } \\
\text { Mostrar, de forma lúdica, como utilizar internet de forma segura; } \\
\text { Realizar análise de casos polêmicos, encontrados na internet, sobre ética digital; } \\
\text { Criar uma tabela associativa entre crimes digitais e os do mundo físico, disponibilizando em } \\
\text { redes sociais e realizando reflexões e debates sobre os mesmos; } \\
\text { Atividades com softwares como Scratch, Robomind, para construção de jogos e outras } \\
\text { soluções; } \\
\text { Realizar pesquisa para conhecer softwares de automação. }\end{array}$ \\
\hline
\end{tabular}

Esse trabalho também tem o intuito de demonstrar que habilidades e competências são necessárias para o ensino de Computação ou Computação Educacional. Habilidades estas que devem estar presentes no dia a dia dos professores, como a capacidade de realizar trabalhos vinculados com o projeto pedagógico da escola, utilizando os conceitos da Ciência da Computação, com a capacidade de demonstrar aos educandos como abstrair as informações mais importantes num problema e a capacidade de formar cidadãos que compreendam a realidade social em que vivem, desenvolvendo a capacidade de trabalhar em cooperação uns com os outros, a capacidade de liderança, expressão, interação e troca de informações.

\section{Considerações Finais}

Diante de tão poucos trabalhos sobre esse assunto, considerou-se esta proposta mais um passo em direção a disseminação do Pensamento Computacional na Educação Básica, tornando-o acessível à comunidade escolar. O desenvolvimento do PC é necessário para qualquer pessoa e em todos os momentos da vida. Sua inserção na escola traz vários aspectos positivos e contribui para o processo de construção cognitiva do educando e o prepara para o atual e futuro mercado de trabalho. 
Dentre as necessidades identificadas para trabalhos futuros, destaca-se a elaboração de um processo metodológico para avaliar o nível de assimilação alcançado pelos educandos quando estiverem trabalhando o Pensamento Computacional.

Sabe-se que muitos dados ainda são necessários buscar na literatura internacional e nacional sobre o ensino de Computação em educação básica, pois algumas iniciativas já existem, mas de forma ampla e empírica e não objetiva e científica no Brasil. Não se pode negar que as tecnologias são prioridades do Estado de Pernambuco, que possui suas políticas de educação e tecnologias. No entanto, reconhecer efetivamente, seria ter uma política profissional para a docência de licenciados em Computação, com concurso público para o quadro docente das escolas públicas, dando maior oportunidade à população de competir no mercado de trabalho, com um conhecimento que é eliminatório em atividades avaliativas de emprego.

Neste sentido, esta pesquisa deixa reflexões e contribui para demonstrar que o Ensino de Computação é uma realidade, caso deixem que isto aconteça, mas que se tem que lutar para a sua efetivação, seja estudante de LC, comunidade escolar e sociedade, para que se alcance políticas educacionais de inclusão digital de forma efetiva nos Estados.

\section{Referências}

MATO GROSSO, Secretaria Estadual de Educação, Esporte e Lazer.(2016) O professor frente às novas tecnologias de informação e comunicação. http://www.seduc.mt.gov.br/Paginas/O-professor-frente-\%C3\%A0s-novastecnologias-de-informa $\% \mathrm{C} 3 \% \mathrm{~A} 7 \% \mathrm{C} 3 \% \mathrm{~A} 30$-e-comunica $\% \mathrm{C} 3 \% \mathrm{~A} 7 \% \mathrm{C} 3 \% \mathrm{~A} 30 . a s p x$, Setembro.

KENSKI, Vani Moreira. (2013) Tecnologias e tempo docente. São Paulo: Papirus Editora.

MORAN, José Manuel. (2007) A Educação que desejamos novos desafios e como chegar lá. São Paulo: Papirus Editora,

BLIKSTEIN, Paulo. (2016) O Pensamento Computacional e a reinvenção do computador na educação. http://www.blikstein.com/paulo/documents/online/ol_pensamento_computacional.ht $\mathrm{ml}$, Setembro.

BRASIL. Ministério da Educação. (2016) PDE : Plano de Desenvolvimento da Educação : SAEB : ensino médio : matrizes de referência, tópicos e descritores. Brasília : $\quad$ MEC, $\quad$ SEB; $\quad$ Inep, 2008. http://portal.mec.gov.br/dmdocuments/saeb_matriz2.pdf, Setembro.

. Ministério da Educação. (2017) Sistema de avaliação da educação básica. http://download.inep.gov.br/educacao_basica/saeb/2017/documentos/projeto_basico_ SAEB_2017_V6.pdf, Março.

, MEC. (2017) Base Nacional Comum Curricular. $3^{\mathrm{a}}$ versão. Brasília. http://basenacionalcomum.mec.gov.br/images/BNCCpublicacao.pdf, Junho. Maio.

(2017) Lei No 9394. http://www.planalto.gov.br/ccivil_03/leis/L9394.htm, , (2017) PNE. http://pne.mec.gov.br/images/pdf/pne_conhecendo_20_metas.pdf, Junho. 
VI Congresso Brasileiro de Informática na Educação (CBIE 2017)

Anais dos Workshops do VI Congresso Brasileiro de Informática na Educação (WCBIE 2017)

BELL, Tim; WITTEN, Ian H.; FELLOWS, Mike. (2016) Computer Science Unplugged Ensinando Ciência da Computação sem o uso do computador. http://csunplugged.org/wp-content/uploads/2014/12/CSUnpluggedTeachersportuguese-brazil-feb-2011.pdf, Setembro.

GERHARDT, Tatiana Engel; SILVEIRA, Denise Tolfo (Orgs.). (2009) Métodos de Pesquisa. Porto Alegre: Editora da UFRGS.

YADAV, Aman. Et. All.. (2017) Computational Thinking for Teacher Education. COMMUNICATIONS OF THE ACM. https://cacm.acm.org/magazines/2017/4/215031-computational-thinking-for-teachereducation/fulltext, Junho.

TUCKER, Allen, Et. All. (2017) A Model Curriculum for K-12 Computer Science. CSTA. https://www.acm.org/education/education/curric_vols/k12final1022.pdf, Junho.

RIBEIRO, Leila. (2016) Computação na Educação Básica. Comissão de Computação na Educação Básica da SBC. Porto Alegre: UFRGS.

WANGENHEIM, Christiane Gresse von, Et. All. (2014) Resumo de Objetivos de Aprendizagem de Computação no Ensino Fundamental (Currículo de Referência CSTA/ACM K-12). Santa Catarina. UFSC.

CAMBRAIA, Adão C.; SCAICO, P. D. (2013) Os desafios da Educação em Computação no Brasil: um relato de experiências com Projetos PIBID no Sul e Nordeste do país. Maringá: Revista Espaço Acadêmico - No 148, Setembro. 